\title{
Case Based Game: Integrating the Practice Framework with Cases
}

\section{Elizabeth Fain*}

\author{
Department of Occupational Therapy, Winston-Salem State University, North Carolina, USA
}

*Corresponding author: Elizabeth Fain, Department of Occupational Therapy, Winston-Salem State University, North Carolina, USA Occupational Therapy, FL Atkins 446, USA, Tel: 336-750-8854, Fax: 336-750-3173, E-mail: fainea@wssu.edu

\begin{abstract}
Introduction: Understanding the Occupational Therapy Practice Framework (OTPF) and its integration with newly learned clinical skills requires students to progress from early information acquisition of the OTPF to synthesis and application to case studies. Active learning facilitates clinical reasoning and is defined as planning, directing, performing and reflecting on client care [1]. However, studies according to Arum [2] report that students are not learning critical thinking, which is precursor to clinical reasoning. The purpose of this study was to investigate the effectiveness of this casebased educational board game developed to reiterate to the Occupational Therapy (OT) students the OTPF [3] and facilitate integration, and clinical reasoning with the course content in a real-time Think Aloud process. Studies reflect that lecture-based delivery does not enhance critical thinking and complex reasoning in the college age learner [2]. Therefore, strategies that result in deeper learning, such as constructivist or humanistic pedagogies should be implemented [4]. Gaming theory is a constructivist and motivational tool that engages learners in sustained engagement for learning.
\end{abstract}

Methodology: This study utilized experimental design with repeated measures pre- and post-test design utilizing the game, Tactful Ps and Qs as the intervention. Sample of convenience consisted of 27 OT students enrolled in an interventions course. The pre-test included several open response questions on the first day of class and the post-test was on the last day of class.

Results: Data analysis on the pre- and post-tests utilized a paired t-test in excel for the two scores. Statistical significance noted reflected that the Tactful Ps and Qs game might be an effective intervention for constructing understanding and application of the Occupational Therapy Practice Framework (OTPF) and integration to case studies.

Implications: This study yields conceptual and practical applications for faculty to consider Think Aloud games as a constructivist-learning tool.

\section{Introduction}

Facilitating retention and integration of core concepts for clinical reasoning is challenging but critical according to the American Occupational Therapy Association's Centennial Vision [5]. It is also essential that students are applying these core concepts to the core practice framework. The Occupational Therapy Practice Framework (OTPF) is the framework that guides and informs the public and the occupational therapy practice about the core beliefs of occupational therapy to promote engagement in their occupational tasks of interest, which ultimately promotes wellness. Creating effective teaching strategies for Occupational Therapy (OT) students to apply the OTPF components to a case based client is challenging for occupational therapy educators given that students focus on memorization of the core concepts. According to Torciva \& Gupta [6] it is especially challenging to students to apply the OTPF and clinical reasoning to complex scenarios that are not structured. Students often focus on memorization of the core concepts of the conditions and interventions, while ignoring or forgetting the occupational therapy framework and the occupational based premise [7]. This study will focus on a custom developed game that applies principles of effective adult learning strategies and gaming theory in order to facilitate deeper clinical reasoning and integration of the practice framework.

\section{Background/Literature Review}

Critical thinking is an essential skill that potential employers want their employees to have [2]. However, scores for critical thinking are not yielding improving scores in critical thinking for college students (Arum, 2011) [2]. Teaching is a multitasking process to facili-

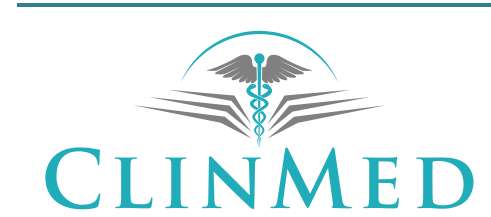

INTERNATIONAL LIBRARY
Citation: Fain E (2017) Case Based Game: Integrating the Practice Framework with Cases. Int Arch Nurs Health Care 3:077. doi.org/10.23937/2469-5823/1510077

Received: May 30, 2017: Accepted: August 04, 2017: Published: August 07, 2017

Copyright: () 2017 Fain E. This is an open-access article distributed under the terms of the Creative Commons Attribution License, which permits unrestricted use, distribution, and reproduction in any medium, provided the original author and source are credited. 
tate learning. Research data about using lecture as a primary pedagogy routinely yields lower scores for understanding course material and critical thinking [8]. Active teaching techniques are prerequisite to facilitate clinical skills and critical thinking learning $[9,10]$. Although, there are many active teaching approaches, deliberate reflective decision-making should occur when planning and determining the types of learning activities that will be utilized [8]. This lays the groundwork for considering utilizing a game for integrating the OTPF with the course conditions and interventions.

Instructional methods that promote higher-level understanding of concepts are essential for developing clinical decision-making; therefore, critical for inclusion in teaching [11]. Active engagement with the course material is essential for learning $[9,10]$. An active student-centered teaching approach promotes deeper levels of thinking and information processing to create constructive meaning making and retention. In class, activities are the most effective for promoting higher- level knowledge with real time feedback [8]. Games are an innovative strategy for actively engaging students, eliciting critical thinking with replication of real world scenarios. Replication of cases with real world scenarios promotes transfer of learning [12].

The conceptual theories for this case based instructional game included the following theoretical frameworks: gaming, Think Aloud, and Gagne's nine events of instruction. Gaming theory incorporates active constructivism learning yet taps into motivational theories that engage learners in more sustaining engagement [13]. Adult students value learning activities that facilitate coping with real life situations [14]. Well-planned games have the potential to stimulate learning on many levels [13]. Games promote sharing of knowledge between the students and development of critical thinking [13] Review of literature for research on games in healthcare education has also yielded positive results for intervention groups with games with $91 \%$ of the students reporting games as an effective method for learning content [13]. According to Cowen \& Tesh [13], the students reported that the utilization of games increased their ability to retain the course material and it made learning fun. Gaming theory as defined by Osborne [15] is a "bag of analytical tools designed to help us understand the phenomena that we observe when decision-makers interact" (p.1). A game used as a learning activity includes cooperation and or competitive elements amongst players/students.

\section{Theoretical framework}

Think Aloud is a cognitive mode of assessment that occurs concurrently during the performance of the learning tasks [16]. Traditional assessment of students' understanding is challenging to elicit in real time utilizing conventional learning assessments. Think Aloud is a cognitive mode of evaluation of learning that allows assessment of cognition and understanding concurrently with the task, in lieu of the learner submitting a written assignment and then receiving the instructors' written feedback later. Immediate verbal comments provided during the processes there by allows all classroom learners to learn from the process as opposed to written feedback for learning in a silo [16]. Think Aloud is a distinguished method of analyzing and making visible, learners' thought processes in nursing courses that the students were required to problem solve complex clinical cases [16]. According to Young [17], listening to students' thought processes while they are engaged in an authentic task is under-utilized. Capturing students' thought processes facilitates concurrent and retrospective probing to the case specific questions. Greater meaning and construction of knowledge occurs when learners are given time to process and create new knowledge [18].

\section{Gagne's nine events of instruction}

Robert Gagne [19] reported that certain learning conditions must be present in order for knowledge absorption and retention to occur. The information processing theory guided the development of Gagne's instructional model. Gagne purports that effective learning frameworks include nine events. These nine events of effective learning include the following: 1) Gains attention, 2) Provides a learning objective, 3) Stimulates recall of prior knowledge, 4) Presents the material in chunks 5) Provides guidance for learning, 6) Elicits performance, 7) Provides feedback, 8) Assesses performance, and 9) Enhances retention and transfer. Refer to Table 1 for descriptions and application of these nine events of learning facilitated in the Tactful Ps and Qs game [19].

\section{Game tactful Ps \& Qs}

The Tactful Ps and Qs game was the learning tool and intervention developed and investigated for effectiveness in this study. The development of this game included the essential criteria for educational games [20]. The criteria addressed were: 1 ) The learning objectives and learning needs, 2) The institutional curriculum and 3) A pre-and post-test to evaluate the student learning. The conceptual design of the Tactful Ps \& Qs game addressed the course learning objectives to enable the students to compare, contrast, generalize and categorize the conceptual frameworks of occupational therapy. Social interaction between students and the educators in a Think Aloud mode was utilized to facilitate deeper processing with simultaneous real time assessment and feedback.

The name of the game depicts the objectives of the game. The definition of tactful is intentional or deliberate. The term Ps and Qs is a term for focusing on behaviors. Together these words form the acronym for the intentional focus of this board game as related to the OTPF and application to case studies related to the course content. 
Table 1: Gagne's events of instruction elicited during tactful Ps \& Qs game.

\begin{tabular}{|c|c|}
\hline $\begin{array}{l}\text { Gagne's nine events of } \\
\text { instruction }\end{array}$ & $\begin{array}{l}\text { Illustration of how students demonstrated the events of instruction during the } \\
\text { Tactful Ps \& Qs game }\end{array}$ \\
\hline Gains attention & $\begin{array}{l}\text { Gained the attention of the students due to the novelty and "real world" aspect of the } \\
\text { game. Students continued engagement past the end of the designated class period. }\end{array}$ \\
\hline Provides a learning objective & $\begin{array}{l}\text { Students understood the explicit and implicit objectives of the game and constructed } \\
\text { meaning throughout the game that relate to the course content and objectives. }\end{array}$ \\
\hline Stimulates recall of prior knowledge & Students recalled prior learning throughout the game for OTPF, and course concepts. \\
\hline Presents the material in chunks & $\begin{array}{l}\text { Integration of the core course concepts in the cases facilitated selective application and } \\
\text { integration by all students engaged in the game in some capacity. }\end{array}$ \\
\hline Provides guidance for learning & $\begin{array}{l}\text { Guidance facilitated accurate responses for mastery and additional higher-level responses } \\
\text { from classmates by providing additional thought provoking questions and scenarios } \\
\text { related to the case utilized in the gaming session. }\end{array}$ \\
\hline Elicits performance & $\begin{array}{l}\text { The game elicited verbal responses to the game case based question cards related to the } \\
\text { OTPF. Responses depicted their level of understanding of the case and the OTPF. }\end{array}$ \\
\hline Provides feedback & $\begin{array}{l}\text { Verbal feedback given throughout the game related to their responses. Additional } \\
\text { scenarios or questions evoked higher-level responses. }\end{array}$ \\
\hline Assesses performance & $\begin{array}{l}\text { Performance assesses throughout the game with feedback and additional verbal } \\
\text { suggestions given. The game allowed all students to see content areas that they not } \\
\text { mastered. }\end{array}$ \\
\hline $\begin{array}{l}\text { Enhances retention and transfer of } \\
\text { knowledge }\end{array}$ & $\begin{array}{l}\text { Enhancement of retention and transfer of knowledge to the cases and real world practice } \\
\text { achieved throughout the game through discussions elicited. Pre and post-test scores also } \\
\text { validated the retention and transfer of knowledge to the questions related to the plan of } \\
\text { care and the OTPF. }\end{array}$ \\
\hline
\end{tabular}

Table notes [19].

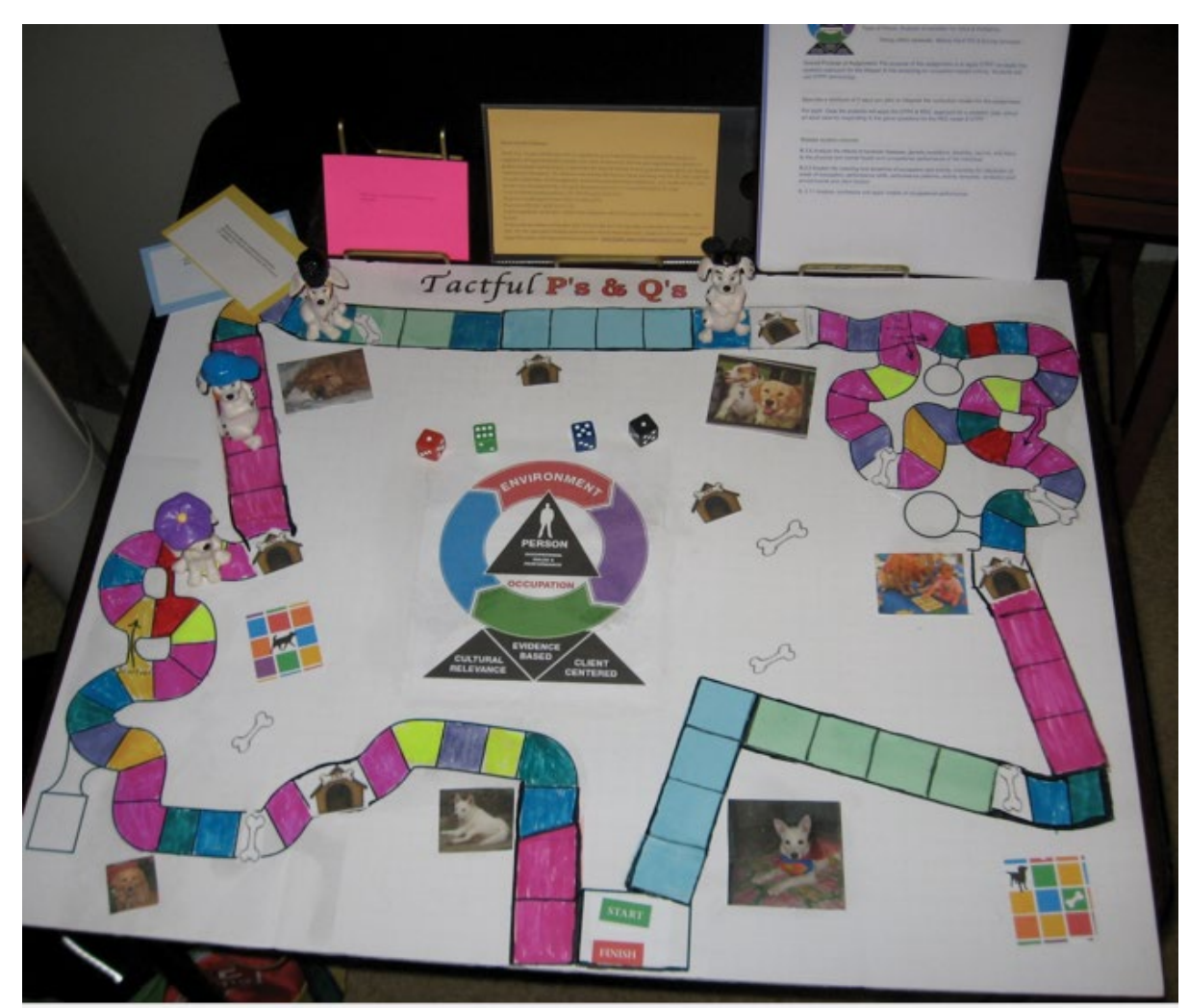

Figure 1: Illustration of tactful Ps \& Qs game board.

T- think

a- aloud

c- critical

t- thinking

f- framework

u- utilizing

l- logical

\section{Ps- practice}

Qs- questions.

There were four to six players directly engaged in the board game. The other students looked on and engaged through additional queries about the game questions for additional and deeper responses. Players rolled the dice, moved their game piece for the number of spaces and drew a question card to respond to as related to 
the preselected cases used throughout the game. Each student verbalized their answer to the question then various students and the instructor responded with additional queries or suggestions for their response and question. The metacognitive responses discussed facilitated awareness and understanding of different options and the rationale for best options. Utilization of responses in a Think Aloud mode during this game facilitated evaluation of individual and group participants' met cognitive processes using the game cases and questions to elicit Think Aloud responses. See Figure 1 which illustrates the Tactful Ps and Qs board game.

The cases were generic and simple cases to more advanced cases to progressively develop think aloud skills and comfort with the game. Questions focused on different aspects of the OTPF, which the student had to recall the OTPF domains, analyze the case and provide the response to each of the cards spontaneously. A sample case might consist of the following: Jose is a 56-yearold construction worker that sustained a hip fracture at work. He has a wife and four children. He loves his family and church. He wants to return to work as soon as possible.

Tactful Ps and Qs Game provides spontaneous think aloud "authentic assessments" of students understanding and application of the OTPF, course content and critical thinking application to the case study in the game. This game enabled students to be aware of their assumptions and others during the critical thinking process. This process also enabled the students to connect the critical thinking process used within the game context and create new knowledge to generate an appropriate treatment plan [6]. Students are required to do the following steps when playing the game.

1) Read the case, which is also on display on the screen for the other students to read.

2) Roll the dice.

3) Advance their game piece for the specified number of spaces.

4) Draw a card corresponding with their game board space color and corresponding OTPF domain.

5) Read the question. Complete the Bloom's cognitive taxonomy domain to respond to the question aloud. Instructor also elicits additional questions from other students in the classroom to promote engagement and deeper understanding for all of the students.

Refer to Table 1 for descriptions and application of the nine events of learning facilitated in the Tactful Ps and Qs game [19].

When the OT students complete these processes, they are connecting the cases to specific concepts, assimilating new conceptual change and receiving immediate feedback along with a reflective debriefing session at the end of the game. This is an authentic assessment, which, consists of responding to the situation simultaneously to the occurrence of the event as opposed to responding to a multiple-choice question and receiving the feedback in a delayed time frame. Students are verbalizing steps for real world tasks for occupational therapists and as a result demonstrating meaningful application of the essential knowledge and skills. While enticing students to engage in learning activities and stimulating their motivation in this case-based game is valuable, the primary benefit of this game is the real time authentic assessment with the Think Aloud socialization which provides students feedback of different levels of reasoning and understanding in a fun, nonthreatening timely manner.

Samples of the questions that the students needed to analyze and apply to the cases if their game piece fell upon that particular game board color. Bloom's taxonomy is a classification system used to define and distinguish different levels of human cognition such as the level of thinking, learning, and understanding. Educators use the Bloom's taxonomy to inform or guide the development of their learning activities and assessments to assess the students' understanding of the content [21]. The Bloom's taxonomy level is also included for the following sample questions:

1. What are the demographics of this case that are relevant to the occupational profile (Bloom's Taxonomy level: Understand, and Analyze)? This question relates to the occupational profile component of an OT Evaluation.

2. What is the onset timeframe of this condition that is relevant for treatment plan and the contraindications and precautions (Bloom's Taxonomy Analyze, Evaluate and (reate)? This question relates to analyzing and integrating the occupational profile component to the OT Intervention plan while considering the contraindications and precautions as related to the condition.

3. Discuss the past medical history and the relevance to the treatment plan (Bloom's Taxonomy Analyze, Evaluate and (reate)? This question relates to analyzing and integrating the occupational profile component to the OT Intervention plan.

4. What body structures are impacted (Bloom's Taxonomy Analyze Evaluate and (reate)? This question relates to analyzing, evaluating and integrating the occupational profile component to the OT Intervention plan.

5. What is the primary role of this client (Bloom's Taxonomy Analyze, Evaluate and Create)? This question relates to analyzing, evaluating and integrating the occupational profile component to the OT Intervention plan. 
6. How will you incorporate this role in your treatments? (Bloom's Taxonomy Analyze Evaluate and Create) This question relates to analyzing and integrating the occupational profile component to the OT Intervention plan.

7. If the age or role of this client were changed, how would the treatment session be different (Bloom's Taxonomy Analyze Evaluate and Create)? This question relates to analyzing and integrating the occupational profile component to the OT Intervention plan.

8. What is the most important problem to consider (Bloom's Taxonomy Analyze and Evaluate)? This question is similar to the questions on the National Board Certification Occupational Therapy exam.

9. Do we need to look at this from another perspective (Bloom's Taxonomy Analyze Evaluate and Create)? This question relates to analyzing and integrating the occupational profile and various OTPF components to the OT Intervention plan.

10. What vitals, positions or activities will need monitoring during the evaluation or treatment (Bloom's Taxonomy Analyze, Evaluate and Create)? Additional questions included questions related to specific treatment planning that integrated the client's occupational roles, interests and diagnosis along with their precautions and contraindications. These questions are similar to the National Board Certification Occupational Therapy certification exam.

11. According Wiggins [22] authentic assessment consists of the following: Requires realistic judgment in a simulated context that represents the workplace and assesses the students ability to apply a repertoire of knowledge and skills to negotiate a complex task. It also allows appropriate opportunities to practice and get feedback on their performance.

\section{Methodology}

Twenty-seven second year Masters of Occupational Therapy students enrolled in Adult Interventions course (which is a required course) participated in this study. These students completed this course and study in the last semester of the program prior to level II field work. The Institutional Review Board of the university approved this investigative study. Students participated with the understanding that this was voluntary without any repercussions if they did not participate. Design was a pre-experimental design study. The intervention consisted of playing the Tactful Ps and Qs game. A pre- and post-test consisted of fill in the blank and essay questions related to the OTPF. All 27 students completed the pre-test to assess base line understanding and recall of the OTPF to establish baseline for later applying to the game based case studies. The pre- and post-test consisted of quiz questions related to the Bloom's domains: recall and understanding of the OTPF domains, while the game focused on application, analysis, evaluation and creation of the information obtained from the OTPF to create an intervention plan. A sample question on the pre- and post-test consisted of the directions, Respond to each of the questions and write your responses. List and define all of the types of contexts included in the OTPF. After completing the pre-test, all of the students actively played the game at least one of the four times during class time. They verbally engaged in the game if they were not actively playing the game. Administration of the final post-test on the OTPF occurred at the end of the semester.

\section{Data Collection}

There were 27 second-year MOT students enrolled in this course/study. Collection of the data occurred during the last semester prior to their level II field work. The written questionnaire instrument consisted of open-ended, short answer questions for the pre- and post-tests specifically for the OTPF and no course material. A blinded and neutral person graded the anonymous and numbered responses using a prerecorded answer sheet.

\section{Intervention}

The intervention consisted of the Tactful Ps and Qs game [23], which was developed for application of the OTPF to the case studies. Students played the Tactful Ps and Qs game class four times after completion of the pre-test throughout their last semester. Cases utilized pertained to recent diagnostic material introduced in the adult interventions class. The game consisted of case questions that corresponded to the different categories of the OTPF. Game participants verbally answered the category questions according to the space that their game piece landed on during the board game. Instructor elicited discussion and feedback from the class, which yielded various responses to engage assessment of the responses and analysis of the best evidence based approach.

\section{Results}

An external grader completed the grading of anonymous and numbered response sheets utilizing an answer sheet. Aggregate data analysis consisted of a paired t-test in excel for the two scores (pre- and posttests). The paired t-test statistic yielded statistically significant scores for all of the pre- and post-test scores ( $p$ $<0.05)$. The data analysis data from the pre- and posttest assessments are in Table 2.

\section{Discussion}

Data yielded statistically significant $p$ values ( $p$ value $=0.00$ ) for learning after the application of the game

Table 2: Pre- and Post-test scores.

\begin{tabular}{|l|l|l|l|l|l|}
\hline $\begin{array}{l}\text { Pre-Test } \\
\text { Means }\end{array}$ & $\begin{array}{l}\text { Pre-Test } \\
\text { SD }\end{array}$ & $\begin{array}{l}\text { Post-Test } \\
\text { Means }\end{array}$ & $\begin{array}{l}\text { Post } \\
\text { SD }\end{array}$ & $\begin{array}{l}\text { P-Value } \\
\text { Computed T } \\
\text { Value }\end{array}$ \\
\hline 64.700 & 12.150 & 75.09 & 7.710 & 0.00 & 3.752 \\
\hline
\end{tabular}

Note: Significance at $p$-value $<0.05$. 
based cases to the OTPF suggesting that they benefitted from playing the Tactful Ps and Qs game despite no additional instruction during that semester related to the OTPF. Although the results of this study are not generalizable to other occupational therapy programs due to the limited sample size, there were some strong interesting findings noted. Additionally, the students reflected on their perceptions and benefits of the game and responses indicated that they benefitted from playing this game, utilizing the thinking aloud techniques, and engaging with the concepts in a fun nonthreatening way.

\section{Limitations}

The limitations of this study were the small convenience sample of 27 OT students from one cohort at one university, which limits the generalization of the findings to other OT programs. Secondly, the pre and posttest questionnaire focused solely on the OTPF. Further studies with larger sample size are warranted to investigate the learning impact on other concepts.

\section{Conclusion and Implications}

In conclusion, the development of the Tactful Ps and Qs game was to promote integration of core concepts for the OTPF with application to clinical case studies. Participation in this game elicited Think Aloud responses for the participants and the class. Pre- and post-formative and summative tests yielded statistically significant improvements as noted in scores despite no additional class time spent on the OTPF in this course or others in the curriculum for that semester. The Tactful Ps and Qs game overwhelmingly points to being an effective instructional tool for the OTPF and application to case studies in this intervention course. Verbal comments, postings on course evaluations and discussions emphasized that the fun and their experience facilitated better comprehensive understanding from this educational game. Utilizing the Tactful Ps and Qs game addressed multiple educational goals and provided deeper learning and an authentic assessment in real time. However, further research to investigate the effectiveness and versatility of this instructional game for additional concepts and a larger sample is warranted.

\section{References}

1. Schell B (2003) Clinical reasoning: The basis of practice. In: EB Crepeau, ES Cohn, BA Schell, Willard \& Spackman's occupational therapy. (10 $10^{\text {th }}$ edn $)$, Lippincott Williams \& Wilkins, Philadelphia.

2. Arum R, Roksa J, Cho E (2011) Improving undergraduate learning: Findings and policy recommendations from the SSRC-CLA Longitudinal Project. Social Science Research Council, New York, USA.

3. American Journal of Occupational Therapy (2014) Occupational therapy practice framework: Domain and process. (3rd edn), 68: S1-S48.

4. Shulman LS (1987) Knowledge and teaching: Foundations for the new reform. Harvard Educational Review 57: 1-23.
5. American Occupational Therapy Association (2006) AOTA's Centennial Vision. Bethesda.

6. Torciva E, Gupta J (2008) Designing learning experiences that lead to critical thinking and enhanced clinical reasoning. OT Practice 13.

7. Forneris SG (2004) Exploring the attributes of critical thinking: A conceptual basis. Int J Nurs Educ Scholarsh 1: 9.

8. Hackathorn J, Solomon E, Tennial R, Garczynski A, Blankmeyer K, et al. (2011) Learning by doing: An empirical study of active teaching techinques. Journal of Effective Teaching 11: 40-54.

9. Peck AC, Ali RS, Matchock RL, Levine ME (2006) Introductory psychology topics and student performance: Where's the challenge? Teaching of Psychology 33: 167-170.

10. McGlynn, Angela Provitera (2005) Teaching millennials, our newest cultural cohort. Educational Digest 71: 12-16.

11. Serva M, Fuller M (2004) Aligning what we do and what we measure in business schools: Incorporating active learning and effective media use in the assessment of instruction. Journal of Management Education 28: 19-38.

12. Rowell S, Spielvogle S (1996) Wanted: "A few good bug detectives", a gaming technique to increase staff awareness of current infection control practices. J Contin Educ Nurs 27: $274-278$.

13. Cowen K, Tesh AS (2002) Effects of gaming on nursing students' knowledge of pediatric cardiovascular dysfunction. J Nurs Educ 41: 507-509.

14. Knowles M, Holton E, Swanson R (1998) The Adult Learner: The Definitive Classic in Adult Education and Human Resource Development. ( $5^{\text {th }}$ edn), Butterworth-Heinemann, Woburn, MA.

15. Osborne M (2004) An Introduction to Game Theory. New York: Oxford University Press.

16. Callin M, Ciliska D (1983) Revitalizing problem solving with triple jump. Canadian Nursing 79: 41-43.

17. Young K (2005) Direct from the source: The value of 'thinkaloud' data in understanding learning. Journal of Educational Enquiry 6: 19-33.

18. McKeachie W (2002) McKeachie's teaching tips: Strategies, research and theory for college and university teachers. $\left(11^{\text {th }} \mathrm{edn}\right)$, Houghton Mifflin, Boston.

19. Gagne R (1987) Instructional Technology Foundations. Lawrence Erlbaum Association, Hillsdale, NJ.

20. Clark C (1976) Simulation gaming: a new teaching strategy in nursing education. Nurse Educ 1: 4-9.

21. S Abbott (2014) The glossary of education reform. Hidden curriculum.

22. Wiggins Grant (1998) Ensuring authentic performance. In: Educative Assessment: Designing Assessments to Inform and Improve Student Performance. ( $1^{\text {st }}$ edn $)$, Jossey-Bass, San Francisco, 21-42.

23. Fain E (2015) Tactful Ps \& Qs game. 